\title{
FAKTOR-FAKTOR YANG MEMPENGARUHI RETENSI PASIEN METADON DI UPT PUSKESMAS KABUPATEN BADUNG
}

\author{
(FACTORS AFFECTING THE RETENTION OF METADON PATIENTS \\ IN UPT HEALTH CENTER OF BADUNG REGENCY)
}

\author{
NI NYOMAN WAHYU UDAYANI ${ }^{\bullet}$, HERLEEYANA MERIYANI ${ }^{1}$, \\ WORO ENJANG SANTI PRIHATIN ${ }^{1}$ \\ ${ }^{1}$ Fakultas Farmasi Universitas Mahasaraswati Denpasar, Jalan Kamboja No 11 A Denpasar Bali
}

\begin{abstract}
Abstrak: HIV dan Narkoba merupakan persoalan besar yang dihadapi bangsa Indonesia. Penularan HIV di kalangan penasun menjadi salah satu modus penularan HIV di Indonesia. Berdasarkan kondisi ini, pemerintah melaksanakan pengembangan pengurangan dampak buruk (harm reduction) bagi penasun. Salah satu strategi yang dikembangkan adalah program terapi rumatan metadon (PTRM). Penelitian ini bertujuan untuk mengetahui gambaran dan faktor-faktor yang berhubungan dengan retensi pasien Program Terapi Rumatan Metadon di salah satu Puskesmas Kabupaten Badung sebagai indikator keberhasilan program. Penelitian ini merupakan penelitian cross sectional untuk mengetahui faktor-faktor yang berhubungan dengan retensi pasien terapi rumatan metadon. Data diperoleh dari melihat rekam medis dan data formulir asesmen wajib lapor dan rehabilitasi medis. Subjek penelitian ini adalah semua pasien di salah satu Puskesmas di Kabupaten Badung. Pengambilan data dilakukan dengan metode purposive sampling. Penelitian dilakukan terhadap 40 responden penelitian. Analisis data dilakukan secara statistic dengan taraf kepercayaan $95 \%$. Hasilnya menunjukkan bahwa bahwa pasien di salah satu Puskesmas Kabupaten Badung sebagian besar memiliki retensi $\geq 1$ tahun yaitu 36 pasien $(90 \%)$ dan retensi $<1$ tahun yaitu 4 pasien $(10 \%)$. Berdasarkan hasil uji fisher diketahui terdapat dua faktor yang berhubungan signifikan dengan retensi yaitu pekerjaan dan dosis $(\mathrm{p}<0,05)$.
\end{abstract}

Kata kunci: metadon, retensi, rumatan

\begin{abstract}
HIV and Drugs is a major problem facing the nation of Indonesia. HIV transmission among IDUs has become one of the modes of HIV transmission in Indonesia. Based on these conditions, the government is carrying out the development of harm reduction for IDUs. One strategy developed is the methadone maintenance therapy program (PTRM). This study aims to determine the description and factors related to patient retention of the Methadone Maintenance Therapy Program in one of the Badung District Health Centres as an indicator of the success of the program. This study is a cross sectional study to find out factors related to patient's retention of methadone maintenance therapy. Data obtained from viewing medical records and assessment data forms compulsory medical reporting and rehabilitation. The subjects of this study were all patients in one Puskesmas in Badung Regency. Data is collected by purposive sampling method. The study was conducted on 40 research respondents. Data analysis was performed statistically with a confidence level of $95 \%$. The results showed that most patients in one of the Badung District Health Centres had $\geq 1$ year retention of 36 patients $(90 \%)$ and retention $<1$ year of 4 patients $(10 \%)$. Based on results the fisher test, it is known that there are two factors that are significantly related to retention, namely occupation and dose ( $\mathrm{p}<0.05)$.
\end{abstract}

Keywords: maintenance, methadone, retention

\section{PENDAHULUAN}

HIV dan Narkoba merupakan persoalan besar yang dihadapi bangsa Indonesia dan bangsabangsa lain di dunia. Dampak negatif yang ditimbulkan oleh HIV dan Narkoba, baik fisik, psikis, sosial, ekonomi, dan budaya, menjadi alasan yang kuat untuk pentingnya penanggulangan HIV dan Narkoba. AIDS yang pertama di Indonesia ditemukan pada 1987 di Bali, pada kasus homoseksual berkewarganegaraan asing. Masuknya heroin sebagai salah satu Napza utama yang disalahgunakan pada awal tahun 90an membawa kekhawatiran terjadinya kenaikan penularan HIV melalui penyuntikan Napza. Hal ini terbukti, dimana pada pertengahan tahun 90an belum ada kasus HIV dari kalangan pengguna Napza suntik (penasun) yang dilaporkan, namun

\footnotetext{
• email korespondensi: udayani.wahyu@unmas.ac.id
} 
kemudian melonjak hingga 50 kali lipat di awal tahun 2000. Mulai kurun waktu ini hingga 2008, penularan HIV di kalangan penasun menjadi modus utama penularan HIV baru di Indonesia. Berdasarkan kondisi ini, pemerintah melaksanakan pengembangan pengurangan dampak buruk (harm reduction) bagi penasun. Salah satu strategi yang dikembangkan adalah program terapi rumatan metadon (PTRM). Strategi ini banyak negara telah memberikan dampak signifikan dalam menekan laju prevalensi HIV. Terdapat bukti perubahan perilaku ke arah positif, diantaranya penurunan perilaku menyuntik, peningkatan kualitas hidup, penurunan depresi dan dampak positif lainnya. (Kemenkes,2017).

Terapi substitusi yang dilakukan dengan cara memberikan obat oral metadon ini terbukti cukup efektif dalam meningkatkan kesejahteraan pasien agar dapat kembali melakukan aktivitas pekerjaan dalam masyarakat. Salah satu program substitusi adalah PTRM. PTRM sendiri memiliki dua tujuan pilihan. Tujuan pertama yaitu untuk membantu pecandu agar berhenti menggunakan narkoba yang diganti dengan metadon yang dikurangi secara bertahap selama jangka waktu tertentu sedangkan tujuan kedua yaitu untuk mengurangi dampak buruk yang diakibatkan oleh penggunaan NAPZA suntikan. PTRM dipercaya paling bermanfaat untuk menangani ketergantungan opioid serta mengurangi bahaya akibat penggunaannya.

Drop out dapat didefinisikan tidak minum obat dalam waktu 7 hari berturut-turut tanpa alasan (Kemenkes,2006). Retensi merupakan jumlah hari penyerapan metadon pertama hingga putus selama satu tahun (365 hari) (Jiang et al,2014). Penelitian di America menunjukkan bahwa rumatan metadon adalah prediktor yang penting dalam merubah perilaku pasien jika pasien bertahan pada program tersebut dalam kurun waktu yang signifikan. (Broome et al,1999). Drug Abuse Reporting Program (DARP) di Amerika menyimpulkan bahwa jangka waktu 3 bulan adalah waktu minimal untuk memperoleh perubahan yang signifikan dari berbagai program. Penelitian lain menunjukkan bahwa $7 \%$ hingga $64 \%$ akan meninggalkan program rumatan metadon secara premature dalam 6 bulan pertama. Hal ini berarti efek terapeutik program metadon hanya dapat dialami oleh beberapa pasien yang mampu bertahan pada program tersebut dalam jangka panjang.(Ward et al, 1992). Hal ini sejalan dengan yang terjadi hingga Agustus 2004 di RSKO Jakarta yang menunjukkan angka drop out $75 \%$ sebelum 5 bulan menjalani program. (Depkes,2007). Pemberian metadon pada Program Terapi Rumatan Metadon memang sudah terbukti dapat membantu mengurangi ketergantungan opiat. Sayangnya, muncul masalah baru yang mengancam keberhasilan program ini, yaitu DO (drop out) pasien terapi metadon. Keluar dari terapi metadon atau drop out akan berakibat pada keinginan pasien untuk kembali lagi mengonsumsi heroin (Rahayu, 2013). Pasien yang putus terapi atau drop out berkisar antara 40\% hingga 50\% dikarenakan berbagai alasan, diantaranya dosis yang kurang, hambatan untuk mengakses program setiap hari, dan ketidakyakinan akan efektivitas program (Sarasvita, 2012).

Salah satu puskesmas di Kabupaten Badung merupakan salah satu Satelit Uji Coba yang pertama kali ada di Indonesia melalui ditetapkannya Keputusan Menteri Kesehatan Nomor 494/Menkes/SK/VII/2006. Berdasarkan hal tersebut, peneliti ingin mengetahui gambaran dan faktor-faktor yang berhubungan dengan retensi pansies Program Terapi Rumatan Metadon di salah satu Puskesmas Kabupaten Badung sebagai indikator keberhasilan program.

\section{METODE PENELITIAN}

Jenis penelitian ini adalah observasional untuk mengetahui faktor-faktor yang berhubungan dengan retensi pasien terapi rumatan metadon. Data diperoleh dari melihat rekam medis dan data formulir asesmen wajib lapor dan rehabilitasi medis. Subjek penelitian ini adalah semua pasien PTRM yang ada di salah satu Puskesmas Kabupaten Badung yang memenuhi kriteria inklusi:

a. Pasien yang berusia 18-65 tahun.

b. Pasien yang sudah terdaftar dalam program terapi metadon minimal 1 tahun sampai penelitian ini dilakukan atau sudah keluar dari terapi metadon saat penelitian ini dilakukan.

c. Pasien PTRM yang memiliki rekam medis yang lengkap.

Kriteria Eksklusi adalah sebagai berikut:

Pasien rujukan sementara dari luar PTRM UPT Puskesmas Kabupaten Badung.

Teknik sampling dalam penelitian ini menggunakan teknik purposive sampling berdasarkan pada suatu pertimbangan tertentu yang dibuat oleh peneliti sendiri, berdasarkan ciri atau 
sifat-sifat populasi yang sudah diketahui sebelumnya (Soekidjo, 2010).

Penelitian dilakukan terhadap 40 responden penelitian yang memenuhi kriteria inklusi. Analisis data dilakukan dengan analisis univariat dan bivariat. Waktu penelitian selama 2 bulan dari bulan Mei 2018 sampai dengan Agustus 2018.

Penelitian ini bermaksud untuk mencari faktor-faktor yang mempengaruhi retensi pasien metadon di PTRM salah satu Puskesmas Kabupaten Badung. Adapun faktor yang akan diteliti antara lain umur, jenis kelamin, pendidikan, pekerjaan, dosis metadon, dosis bawa pulang, dan dukungan keluarga. Penelitian ini menggunakan instrument berupa formulir/lembar pengambilan data.

Analisis data menggunakan uji fisher untuk melihat pengaruh masing-masing variabel terhadap retensi. Variabel yang diuji antara lain umur, jenis kelamin, pendidikan, pekerjaan, dosis metadon, dosis bawa pulang, dan dukungan keluarga.

\section{HASIL DAN PEMBAHASAN}

\section{Karakteristik Subyek Penelitian}

Tabel 1. Karakteristik Subyek Penelitian

\begin{tabular}{|c|c|c|c|}
\hline No & $\begin{array}{c}\text { Karakteristik } \\
\text { Subjek Penelitian }\end{array}$ & Jumlah & Persentase \\
\hline \multirow{3}{*}{1} & Umur: & & \\
\hline & $\leq 25$ tahun & 1 & $2,5 \%$ \\
\hline & $>25$ tahun & 39 & $97,5 \%$ \\
\hline \multirow{3}{*}{2} & Jenis kelamin: & & \\
\hline & Perempuan & 4 & $10 \%$ \\
\hline & Laki-laki & 36 & $90 \%$ \\
\hline \multirow{3}{*}{3} & Pendidikan: & & \\
\hline & Menengah & 33 & $82,5 \%$ \\
\hline & Tinggi & 7 & $17,5 \%$ \\
\hline \multirow{3}{*}{4} & Pekerjaan: & & \\
\hline & Swasta & 18 & $45 \%$ \\
\hline & Wiraswasta & 22 & $55 \%$ \\
\hline \multirow{3}{*}{5} & Retensi: & & \\
\hline & $<1$ tahun & 4 & $10 \%$ \\
\hline & $\geq 1$ tahun & 36 & $90 \%$ \\
\hline
\end{tabular}

Berdasarkan hasil tersebut maka diketahui terdapat dua faktor yang berhubungan signifikan dengan retensi. Faktor tersebut adalah pekerjaan dan dosis. Faktor pekerjaan memiliki nilai signifikan sebesar 0,033 . Hal ini berarti pekerjaan berhubungan signifikan dengan retensi. Berdasarkan tabel tersebut, diketahui bahwa pekerjaan sebagai wiraswasta cenderung memiliki retensi lebih dari 1 tahun sebanyak 22 orang. Sedangkan pekerjaan sebagai swasta yang memiliki retensi kurang dari 1 tahun sejumlah 4 orang.

Faktor dosis memiliki nilai signifikan sebesar 0,026. Hal ini berarti dosis berhubungan signifikan dengan retensi. Berdasarkan tabel tersebut, diketahui bahwa dosis lebih besar dari 60 mg cenderung memiliki retensi lebih dari 1 tahun sebanyak 23 orang. Sedangkan dosis yang kurang dari $60 \mathrm{mg}$ yang memiliki retensi kurang dari 1 tahun sejumlah 4 orang.

Tabel 2. Tabel Multivariat

\begin{tabular}{llc}
\hline No & $\begin{array}{c}\text { Faktor - faktor yang } \\
\text { berhubungan dengan } \\
\text { Retensi }\end{array}$ & $\begin{array}{c}\boldsymbol{P}(>\mathbf{0 . 0 5}) \\
\text { tidak ada } \\
\text { pengaruh }\end{array}$ \\
\hline $\mathbf{1}$ & Umur & 0.100 \\
\hline $\mathbf{2}$ & Jenis kelamin & 0.355 \\
\hline $\mathbf{3}$ & Pendidikan & 0.134 \\
\hline $\mathbf{4}$ & Pekerjaan & 0.033 \\
\hline $\mathbf{5}$ & Dosis & 0.026 \\
\hline $\mathbf{6}$ & Dosis Bawa Pulang & 1.000 \\
\hline $\mathbf{7}$ & Dukungan Keluarga & 1.000 \\
\hline
\end{tabular}

Hubungan antara umur terhadap retensi, hasil analisis diperoleh bahwa nilai Exact Fisher yang diperoleh sebesar 0,100 . Nilai tersebut lebih dari 0,05 , sehingga diputuskan bahwa terima Ho, yang berarti bahwa tidak ada hubungan yang signifikan antara umur terhadap retensi. Hal ini berarti bahwa umur responden tidak mempengaruhi retensi pasien. Hal ini sesuai dengan penelitian lain yang menunjukkan faktor umur tidak mempengaruhi retensi pasien (Tri Rahayu dkk, 2013)

Hubungan antara jenis kelamin terhadap retensi, hasil analisis diperoleh bahwa nilai Exact Fisher yang diperoleh sebesar 0,355 . Nilai tersebut lebih dari 0,05 , sehingga diputuskan bahwa terima Ho, yang berarti bahwa tidak ada hubungan yang signifikan antara jenis kelamin terhadap retensi. Hal ini berarti bahwa jenis kelamin responden tidak mempengaruhi retensi pasien. Hal ini sesuai dengan penelitian lain yang menunjukkan faktor jenis kelamin tidak mempengaruhi retensi pasien. (Tri Rahayu dkk, 2013)

Hubungan antara pendidikan terhadap retensi, hasil analisis diperoleh bahwa nilai Exact Fisher yang diperoleh sebesar 0,134 . Nilai tersebut lebih dari 0,05 , sehingga diputuskan bahwa terima Ho, yang berarti bahwa tidak ada hubungan yang signifikan antara pendidikan terhadap retensi. Hal ini berarti bahwa pendidikan responden tidak mempengaruhi retensi pasien. Hal ini sesuai dengan penelitian lain yang menunjukkan faktor 
pendidikan tidak mempengaruhi retensi pasien. (Tri Rahayu dkk, 2013).

Hubungan antara pekerjaan terhadap retensi, hasil analisis diperoleh bahwa nilai Exact Fisher yang diperoleh sebesar 0,033 . Nilai tersebut kurang dari 0,05 , sehingga diputuskan bahwa tolak Ho, yang berarti bahwa ada hubungan yang signifikan antara pekerjaan terhadap retensi. Hal ini berarti bahwa pekerjaan responden mempengaruhi retensi pasien. Hal ini dikarenakan bahwa pekerjaan wiraswasta dimana pasien tidak terikat dengan jam kerja memiliki retensi $\geq 1$ tahun pada terapi metadon. Sebaliknya pasien dengan pekerjaan karyawan swasta yang terikat pada jam kerja dan aturan lain di tempat kerja memiliki retensi $<1$ tahun pada terapi metadon. Hal ini mungkin dikarenakan pengaruh faktor waktu pelayanan PTRM yang dimulai pada pukul 07.30 sampai pukul 14.00 wita yang menyulitkan pasien yang bekerja sebagai karyawan swasta dengan jam kerja yang berbenturan dengan jam layanan PTRM sehingga pasien melewatkan dosis dan akhirnya berhenti dari terapi metadon.

Program terapi metadon tidak diberikan pada pasien dalam keadaan overdosis atau intoksikasi opiat. Penilaian terhadap pasien tersebut dapat dilakukan sesudah pasien tidak dalam keadaan overdosis atau intoksikasi. Pasien harus diobservasi 45 menit setelah pemberian dosis awal untuk memantau tanda-tanda toksisitas atau gejala putus obat. Jika terdapat intoksikasi atau gejala putus obat berat maka dosis akan dimodifikasi sesuai keadaan. Metadona harus diberikan dalam bentuk cair dan diencerkan sampai menjadi $100 \mathrm{cc}$ dengan larutan sirup. Pasien harus hadir setiap hari di klinik. Metadona sesuai resep dokter, akan diberikan oleh tenaga teknis kefarmasian atau perawat yang diberi wewenang oleh apoteker penanggung jawab. Pasien harus segera menelan Metadona tersebut di hadapan petugas PTRM (Kemenkes RI, 2013).

Hubungan antara dosis terhadap retensi, hasil analisis diperoleh bahwa nilai Exact Fisher yang diperoleh sebesar 0,026 . Nilai tersebut kurang dari 0,05, sehingga diputuskan bahwa tolak Ho, yang berarti bahwa ada hubungan yang signifikan antara dosis terhadap retensi. Hal ini berarti bahwa dosis mempengaruhi retensi pasien. $\mathrm{Hal}$ ini sesuai dengan hasil penelitian lain yang menunjukkan semakin tinggi dosis, pasien akan semakin lama berada pada terapi metadon. (Liu dkk, 2009)
Hubungan antara dosis bawa pulang terhadap retensi, hasil analisis diperoleh bahwa nilai Exact Fisher yang diperoleh sebesar 1,000. Nilai tersebut lebih dari 0,05 , sehingga diputuskan bahwa terima Ho, yang berarti bahwa tidak ada hubungan yang signifikan antara dosis bawa pulang terhadap retensi. Hal ini berarti bahwa dosis bawa pulang tidak mempengaruhi retensi pasien.

Hubungan antara dukungan keluarga terhadap retensi, hasil analisis diperoleh bahwa nilai Exact Fisher yang diperoleh sebesar 1,000. Nilai tersebut lebih dari 0,05 , sehingga diputuskan bahwa terima Ho, yang berarti bahwa tidak ada hubungan yang signifikan antara dukungan keluarga terhadap retensi. Hal ini berarti bahwa dukungan keluarga responden tidak mempengaruhi retensi pasien. Hal ini sesuai dengan penelitian lain yang menunjukkan faktor dukungan keluarga tidak mempengaruhi retensi pasien (Tri Rahayu dkk, 2013).

\section{SIMPULAN}

Pasien PTRM di salah satu Puskesmas Kabupaten Badung sebagian besar memiliki retensi $\geq 1$ tahun yaitu 36 pasien $(90 \%)$ dan retensi $<1$ tahun yaitu 4 pasien $(10 \%)$. Dari hasil uji fisher diketahui terdapat dua faktor yang berhubungan signifikan dengan retensi yaitu pekerjaan dan dosis $(\mathrm{p}<0,05)$.

\section{DAFTAR PUSTAKA}

Broome, K. M., Simpson, D. D., \& Joe, G. W. (1999). Patient and program attributes related to treatment process indicators in DATOS. Drug and Alcohol Dependence, 57(2), 127-135.

Depkes, R. I. (2007). Modul dan Kurikulum Pelatihan Program Terapi Rumatan Metadon (PTRM). Jakarta Depkes RI.

Haifeng Jiang et al. (2014). Factors associated with one-year retention to methadone maintenance treatment program among patients with heroin dependence in China. Substance Abuse Treatment, Prevention, and Policy 9:11.

Kemenkes RI. (2006). Keputusan Menteri Kesehatan Republik Indonesia Nomor 567/MENKES/SK/VIII/2006 Tentang Pedoman Pelaksanaan Pengurangan 
Dampak Buruk Narkotika, Psikotropika dan Zat Adiktif (NAFZA). Jakarta: Kemenkes RI.

Kemenkes RI. (2013). Peraturan Menteri Kesehatan Republik Indonesia Nomor 57 Tahun 2013 Tentang Pedoman Penyelenggaraan Program Terapi Rumatan Metadona. Jakarta: Kemenkes RI.

Kemenkes RI. (2017). Modul Pelatihan Program Terapi Rumatan Metadon (PTRM). Jakarta: Kemenkes RI.

Liu, Enwu, Liang, Tao, dkk. (2009). Correlates of Methadone Client Retention: A Prospective Cohort Study in Guizhou Province. China.

M. Sopiyudin Dahlan. 2012, Statistik Untuk Kedokteran dan Kesehatan Edisi 5, Jakarta: Salemba Medika.
Notoatmodjo, S, 2010, Metodologi Penelitian Kesehatan. Jakarta, Rineka Cipta.

Rahayu, T. (2013). Gambaran dan faktor-faktor yang berhubungan dengan retensi pasien program terapi rumatan metadon (PTRM) di Puskesmas Kecamatan Tebet. Jakarta: Fakultas Kesehatan Masyarakat Universitas Indonesia.

Sarasvita, R. (2004). Predictors of Treatment Retention on Metadon Maintenance Program. Baltimore: The Johns Hopkins University.

Sugiyono. 2013. Metode Penelitian Kuantitatif, Kualitatif, dan R\&D. Cetakan ke 19. Bandung: Alfabeta.

Ward, J., Mattick, R. \& Hall, W. (1992). Key Issues in Metadon Maintenance Treatment. Sidney: New South Wales University Press. 